\title{
Upregulation of death receptor 5 and activation of caspase $8 / 3$ play a critical role in ergosterol peroxide induced apoptosis in DU 145 prostate cancer cells
}

Jonghyun $\mathrm{Han}^{\dagger}$, Eun Jung Sohn ${ }^{\dagger}$, Bonglee Kim${ }^{\dagger}$, Sunhee Kim, Gunho Won, Sangwook Yoon, Jihyun Lee, Moon Joon Kim, Hojin Lee, Kyujin Chung and Sung-hoon Kim ${ }^{*}$

\begin{abstract}
Background: Though ergosterol peroxide (EP) derived from Neungyi mushrooms (Sarcodon aspratus) was known to have cytotoxic, apoptotic, anti-inflammatory and antimycobacterial effects, the underlying molecular mechanism of EP still remains unclear. Thus, in the present study, the apoptotic mechanism of EP was elucidated in DU 145 prostate cancer cells.

Methods: Cell viability of prostate cancer cells was measured by MTT assay. To see whether EP induces the apoptosis, FACS, western blot and TUNEL assay were performed. To determine the role of Death receptor (DR) 5 molecules in EP-induced apoptosis in DU 145 prostate cancer cells, the silencing of DR 5 was performed by using SiRNAs.

Results: EP showed significant cytotoxicity against DU 145, PC 3, M2182 prostate cancer cells. Also, EP effectively increased the sub G1 population and terminal deoxynucleotidyl transferase DUTP nick end labeling (TUNEL) positive cells in DU 145 prostate cancer cells. Furthermore, western blotting revealed that EP cleaved poly (ADP-ribose) polymerase (PARP) and caspase 8/3, attenuated the expression of fluorescence loss in photobleaching (FLIP), BCl-xL and $\mathrm{BCl}-2$ as well as activated Bax, Fas-associated death domain (FADD) and DR 5 in a concentration dependent manner in DU 145 prostate cancer cells. Conversely, caspase 8 inhibitor Z-IETD-FMK blocked the apoptotic ability of EP to cleave PARP and an increase of sub G1 population in DU 145 prostate cancer cells. Likewise, the silencing of DR 5 suppressed the cleavages of PARP induced by EP in DU 145 prostate cancer cells.

Conclusion: Overall, our findings suggest that ergosterol peroxide induces apoptosis via activation of death receptor 5 and caspase 8/3 in DU 145 prostate cancer cells as a cancer chemopreventive agent or dietary factor.
\end{abstract}

Keywords: Ergosterol peroxide, Apoptosis, Caspase 8/3, Z-IETD-FMK, DR 5, DU 145 prostate cancer cells

\section{Introduction}

Prostate cancer is the second most frequently diagnosed cancer and the sixth leading cause of cancer death in males worldwide in 2011 [1]. Human prostate cancer cell lines are established including androgen dependent cancer LNCap and androgen independent cancers such

\footnotetext{
* Correspondence: sungkim7@khu.ac.kr

${ }^{\dagger}$ Equal contributors

Cancer Preventive Material Development Research Center, College of

Oriental Medicine, Kyung Hee University, Hoegidong, Dongdaemungu, Seoul 130-701, Republic of Korea
}

as PC 3, TSU-Prl and DU 145 prostate cancer cells [2]. Though modern therapies such as chemotherapy, radiotherapy, surgery and castration have contributed to the treatment and prevention of prostate cancers, prostate cancer still remains refractory disease. Thus, recently herbal medicine [3,4] and phytochemicals [5-8] are attractive as supplements for combination therapy with cancer preventive or therapeutic agents targeting apoptosis, angiogenesis and metastasis.

Apoptosis is the process of programmed cell death (PCD), generally consisting of intrinsic mitochondrial pathway and 
extrinsic cell death pathway. Thus, recently anticancer agents from natural products are attractive by targeting apoptosis in several cancers [9-11]. Sarcodon edible mushroom [12] and its compound ergosterol peroxide (EP) [13], one of $\beta$-D-glucan metabolites, were reported to have antitumor activity in several cancers. Nonetheless, the underlying molecular mechanism of EP was not fully understood in prostate cancer. Thus, in the present study, the underlying apoptotic mechanism of EP was investigated in DU 145 prostate cancer cells targeting extrinsic apoptosis via DR 5 signaling using MTT assay, cell cycle analysis, TUNEL assay, western blotting and inhibitor study using caspase 8 inhibitor Z-IETD-FMK and siRNA transfection of DR 5.

\section{Methods}

\section{Isolation of ergosterol peroxide}

Ergosterol peroxide (EP; Figure 1) was isolated from Neungyi mushrooms (Sarcodon aspratus) as previously described with some modifications [12,14]. In brief, Sarcodon aspratus was extracted with acetone, and then EP was isolated from the acetone extract by using column chromatography (Waters, USA), silica gel column chromatography (Merck, Germany) and reverse-phase HPLC using a C18 column. Ergosterol was precipitated from the eluate of the silica gel column and finally EP was identified as 5-alpha, 8-alpha-epidioxy-22eEergosta-6, 22-dien-3beta-ol with chemical structure shown in Figure 1 by UV spectroscopy, mass spectrometry and ${ }^{13} \mathrm{C}$ - and ${ }^{1} \mathrm{H}-\mathrm{NMR}$. The purity of EP used in this experiment was over $97 \%$.

\section{Cell culture}

DU 145, PC 3, M2182 prostate cancer cells, HCT116 colon cancer cells, A549 lung cancer cells, SKOV3 ovary cancer cells (ATCC $^{\circ} \mathrm{HTB}^{-81^{\mathrm{Tm}}}$ ), and RWPE1 normal benign prostate epithelial cell lines were purchased from American Type Culture Collection (ATCC, Manassas, VA, USA). These cells were cultured in RPMI 1640 medium (Invitrogen, Carlsbad, CA, USA) supplemented with 10\% FBS, 2 mML glutamine, and 100 units $/ \mathrm{ml}$ antibioticantimycotics.

\section{Cytotoxicity assay}

The cell viability was evaluated by using MTT (3(4,5-dimethylthiazol-2-yl)-2,5-diphenyltetrazolium bromide) assay (Sigma, St. Louis, MO, USA). DU 145 prostate cancer were seeded at $1 \times 10^{4}$ cells/well of 96-well flat bottom plate and treated with various concentrations of $\mathrm{EP}(0,25$, 50, 100, 150 and $200 \mu \mathrm{g} / \mathrm{ml}$ ) for $72 \mathrm{~h}$. MTT was added to each well and incubated for $4 \mathrm{~h}$ at $37^{\circ} \mathrm{C}$. Formazen crystals were dissolved by addition of dimethyl sulfoxide (DMSO) solution. The absorbance of each well was determined using the microplate reader (Molecular Devices Co., Sunnyvale, CA, USA) at $570 \mathrm{~nm}$.

\section{Cell cycle analysis}

DU 145 prostate cancer cells treated with EP (25 and $50 \mu \mathrm{M})$ for $24 \mathrm{~h}$ were fixed in $75 \%$ ethanol at $-20^{\circ} \mathrm{C}$, resuspended in PBS containing RNase A $(1 \mathrm{mg} / \mathrm{ml})$, and incubated for $1 \mathrm{~h}$ at $37^{\circ} \mathrm{C}$. Fixed cells were stained with propidium iodide $(50 \mu \mathrm{g} / \mathrm{ml})$ for $30 \mathrm{~min}$ at room temperature in dark. The DNA contents of the stained cells were analyzed using CellQuest Software with the FACSCalibur flow cytometry (Becton Dickinson, Franklin Lakes, NJ, USA). For the inhibitor study, caspase 8 inhibitor Z-IETD-FMK $(20 \mu \mathrm{M})$ was treated in DU 145 prostate cancer cells in the presence or absence of EP for $24 \mathrm{~h}$ for cell cycle analysis.

\section{TUNEL assay}

Individual apoptotic cell death was observed using Dead End TM fluorometric terminal deoxynucleotidyl transferase DUTP nick end labeling (TUNEL) assay kit (Sigma, St. Louis, MO, USA) according to the manufacturer's instructions. Briefly, DU 145 prostate cancer cells treated with EP ( 25 and $50 \mu \mathrm{M})$ were washed with cold PBS. Cells were seeded after fixing with $4 \%$ paraformaldehyde for $30 \mathrm{~min}$ and washed twice with PBS for $2 \mathrm{~min}$. Resuspended cells in permeabilization solution $(0.1 \%$ Triton $\mathrm{X}-100$ and $0.1 \%$ Sodium citrate) for $4^{\circ} \mathrm{C}$ overnight were washed with PBS twice. The cells in $25 \mathrm{ml}$ of TUNEL assay mixture were incubated for $60 \mathrm{~min}$ at $37^{\circ} \mathrm{C}$ in a humidified atmosphere in the dark. The TUNEL-stained cells were counter-stained with propidium iodide (Sigma, St. Louis, MO, USA) and visualized at x200 magnification by fluorescence microscopy (AXIO observer A1, Zeiss, Weimar, Germany).

\section{Western blotting}

Whole cell lysates of DU 145 were prepared by using lysis buffer (50 mM Tris- $\mathrm{HCl}$, pH 7.4, $300 \mathrm{mM} \mathrm{NaCl}, 0.5 \%$ Triton X-100, 5 mM EDTA, 1 mM Na$V_{4}, 1$ mM NaF, $10 \mu \mathrm{g} / \mathrm{ml}$ aprotinin, $10 \mu \mathrm{g} / \mathrm{ml}$ leupeptin, $10 \mu \mathrm{g} / \mathrm{ml}$ pepstatin, $10 \mathrm{mM}$ iodoacetamide, $2 \mathrm{mM}$ PMSF). To measure the protein contents, a Bio-Rad DC protein assay kit II (Bio-Rad, Hercules, CA, USA) was used. The proteins were separated on $10 \%$ tris-glycin gels, and electrotransferred onto a Hybond ECL transfer membrane with transfer buffer (25 mM Tris, $250 \mathrm{mM}$ glycine, 20\% methanol). The membranes were blocked in 5\% nonfat dry milk in TBS buffer containing 0.1\% Tween 20 (TBST) and immunoblotted with antibodies of cleaved caspase 3, cleaved caspase 8 , procaspase 8 , procaspase 9 , PARP, Bcl-2, Bcl- ${ }_{\mathrm{X}} \mathrm{L}$, Bax, DR 5, FLIP and FADD (Cell signaling, Beverly, MA, USA), and $\beta$-actin (Sigma Aldrich Co., St. Louis, MO, USA), and then exposed to horseradish peroxidase (HRP)- 

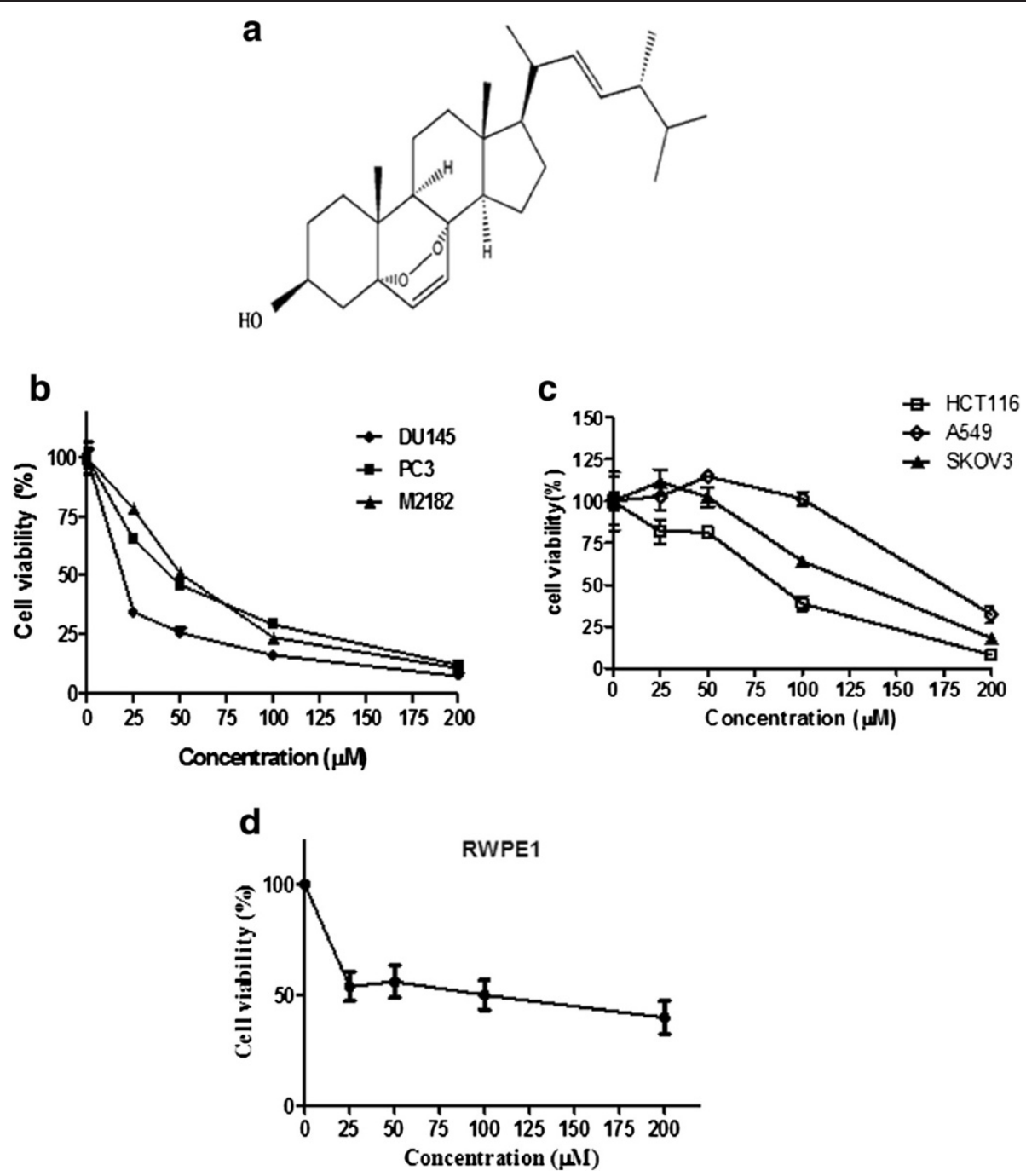

Figure 1 Cytotoxic effect of EP against DU 145 prostate cancer cells. The cells were treated with various concentrations of EP $(0,25,50,100$, and $200 \mu \mathrm{M} / \mathrm{mL}$ ) for $72 \mathrm{~h}$. Then MTT assay was carried out. (a) Chemical structure of EP. (b) Cytotoxicity of EP in DU 145, PC 3 or M2182 prostate cancer cells and (c) HCT116 colon cancer cells, A549 lung cancer cells, SKOV3 ovary cancer cells, and (d) RWPE1 (prostate epithelial cells). Data are presented as means \pm S.D of triplicate samples.

conjugated secondary anti-mouse or rabbit antibodies (AbD Serotec, Raleigh, NC, USA). Protein expression was examined by using enhanced chemiluminescence (ECL) system (Amersham Pharmacia, Piscataway, NJ, USA).

\section{SiRNA DR 5 transfection}

DU 145 prostate cancer cells were transiently transfected with a validated scrambled control siRNA, or siRNA specifically for DR 5 (Santa Cruz Biotechnology, Santa Cruz, CA, USA) by using Interferin ${ }^{\mathrm{TM}}$ transfection reagent (Polyplus-transfection Inc., New York, NY, USA). Briefly, the mixture of siRNA and Interferin ${ }^{\mathrm{Tm}}$ transfec- $^{-}$ tion reagent was incubated for $10 \mathrm{~min}$, added to each well of the cells (siRNA final concentration $=40 \mathrm{nM}$ ) and incubated at $37^{\circ} \mathrm{C}$ for $24 \mathrm{~h}$ before EP treatment.

\section{Statistical analyses}

All data were expressed as means \pm SD. The statistically significant differences compared with untreated group were calculated by Student's $t$-test.

\section{Results}

Cytotoxic effect of EP against DU 145 prostate cancer cells

EP (Figure 1a) exerted significant cytotoxicity against DU 145 prostate cancer cells compared to non-treated cells. To evaluate cytotoxic effect of EP, MTT assay was performed. DU 145 prostate cancer were plated in 96-well plate and treated with various concentrations $(0,25,50,100$, and 200 $\mu \mathrm{M} / \mathrm{ml}$ ) of EP for $72 \mathrm{~h}$. As shown in Figure $1 \mathrm{~b}$, the cytotoxicity of EP was significantly exhibited in concentration dependent manner in DU 145, PC 3 and M2182 prostate cancer cells. Additionally, the cytotoxicity of EP was 
determined in A549 lung cancer cells, HCT116 colon cancer cells, SKOV3 ovary cancer cells (Figure 1c) and RWPE1 (normal prostate epithelial cells) (Figure 1d). MTT assay revealed that EP showed the strong cytotoxic effect in the prostate cancer cells lines such as DU 145, PC 3 or M2182 compared to A549 lung cancer cells,
HCT116 colon cancer cells, SKOV3 ovary cancer cells or RWPE1 cells.

\section{Apoptotic effect of EP in DU 145 prostate cancer cells}

To confirm whether the cytotoxicity of EP was due to apoptosis, cell cycle analysis and TUNEL assay were a

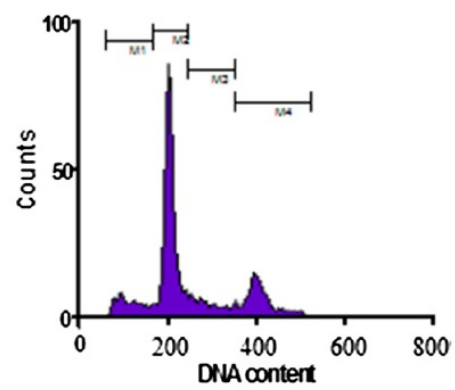

$\mathrm{EP}(50 \mu \mathrm{M})$

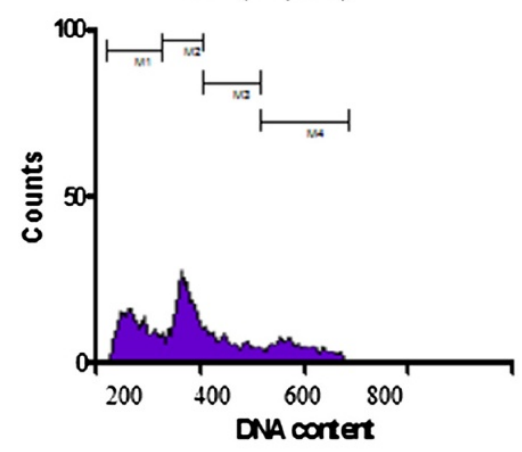

b

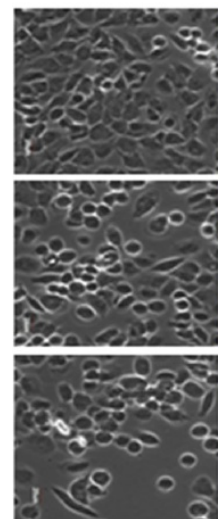

\section{DAPI}

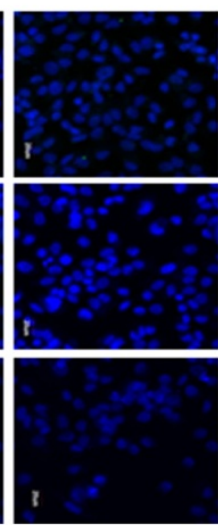

$\mathrm{EP}(25 \mu \mathrm{M})$
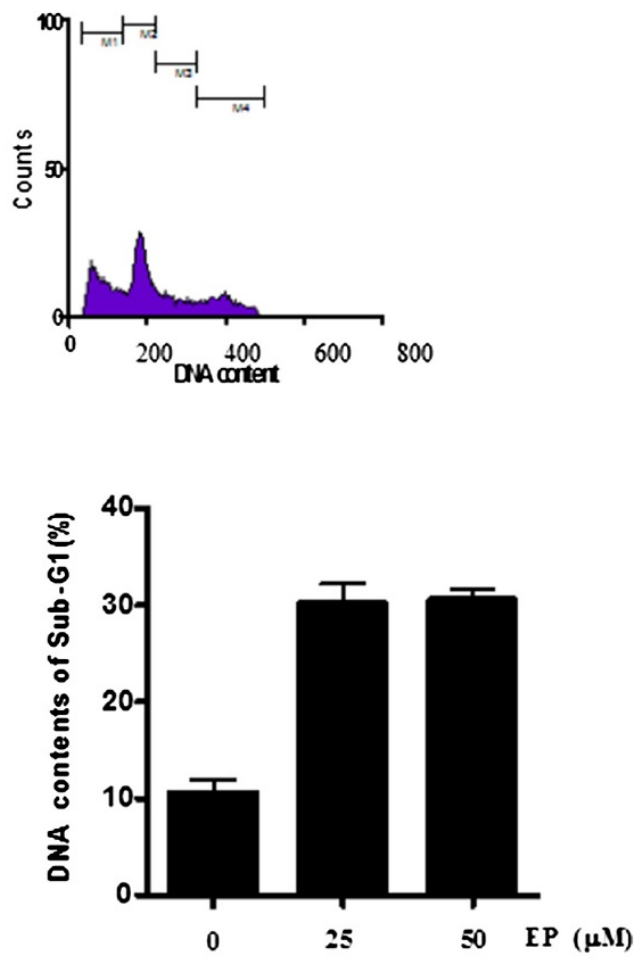

TUNEL

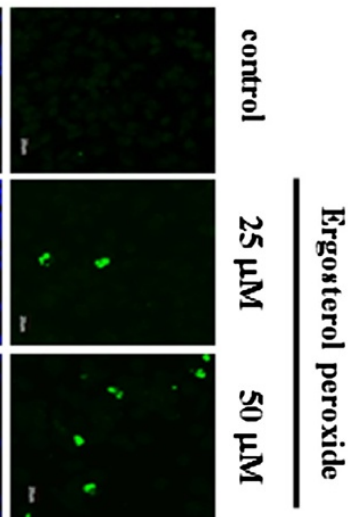

Figure 2 The effect of EP inducing apoptosis in DU 145 cells by cell cycle and TUNEL assay. (a) The effect of EP on sub G1 population in DU 145 cells. DU 145 prostate cancer were exposed to with EP ( 25 and $50 \mu \mathrm{M})$ for $24 \mathrm{~h}$ and stained with propidium iodide $(50 \mu \mathrm{g} / \mathrm{ml})$ for $30 \mathrm{~min}$ at room temperature in dark. Then flow cytometric analysis was performed. Data are presented as means \pm S.D of triplicate samples. (b) Effect of EP on TUNEL assay in DU 145 cells. DU 145 cells treated with EP $(25$ and $50 \mu \mathrm{M})$ were seeded after fixing with 4\% paraformaldehyde for 30 min and incubated in 25 $\mathrm{ml}$ of TUNEL assay mixture for $60 \mathrm{~min}$ at $37^{\circ} \mathrm{C}$ in the dark. TUNEL-stained cells were counter-stained with propidium iodide (Sigma, St. Louis, MO, USA) and visualized at $\times 200$ magnification by fluorescence microscopy. 
performed. In the present study, EP significantly increased sub G1 population (Figure 2a) and also TUNEL positive green colored cells as one of apoptosis features in DU 145 prostate cancer cells (Figure 2b).

\section{Effect of EP on apoptosis related proteins in DU 145 prostate cancer cells}

EP activated extrinsic apoptosis and attenuated survival genes in DU 145 prostate cancer cells. EP activated cleaved PARP, Bax and caspase $8 / 3$, and attenuated the expression of procaspase $8, \mathrm{Bcl}-2, \mathrm{Bcl}_{-\mathrm{X}} \mathrm{L}$ without affecting procaspase 9 from the concentration of $25 \mu \mathrm{M}$ compared to untreated control in DU 145 prostate cancer cells as shown Figure 3a, and b. We also confirmed that EP treatment attenuated procaspase 8 and activated cleaved PARP and cleaved caspase 3 in PC 3 cells (Figure 3c).

\section{Caspase 8 inhibitor Z-IETD-FMK and siRNA DR 5 blocked the apoptotic ability of EP to cleave PARP}

Caspase 8 inhibitor Z-IETD-FMK interrupted the cleavage of PARP induced by EP in DU 145 prostate cancer cells (Figure 4a). Consistently, Z-IETD-FMK suppressed sub G1 population up to $7.1 \%$ and $9.7 \%$, respectively, at the concentrations of 25 and $50 \mu \mathrm{M}$ in EP treated DU 145 prostate cancer cells, while EP enhanced sub G1 population up to $22.8 \%$ and $37.8 \%$ at the same concentrations in DU 145 prostate cancer cells (Figure 4b).

\section{Apoptotic ability of EP via caspase 8, DR 5 in DU 145 prostate cancer cells}

EP treated DU 145 enhanced the expression of FADD, DR 5 and DR 4 while FLIP was attenuated (Figure 5a). To confirm the roles of caspase 8 and DR 5 molecules in EP induced apoptosis in DU 145 prostate cancer cells, the silencing of DR 5 by siRNAs were used. As shown in Figure 5b, siRNA transfection of DR 5 also blocked upregulation of DR 5 and cleavage of PARP and caspase 8 induced by EP in DU 145 prostate cancer cells (Figure 5b) indicating that DR 5 mediates EP induced apoptosis in DU 145 cells.

\section{Discussion}

Neungyi mushrooms have been used as traditional medicine or healthy food for years. Recent studies revealed the multi-biological activities including immunomodulating, anti-inflammatory and anti-cancer effects of mushrooms such as Phellinus linteus, Sarcodon asparatus, Ganoderma applanatum, Paecilomyces tenuipes and Agaricus blazei [15-17].

Though ergosterol peroxide (EP) as a metabolite of $\beta$-glucan, a well known antitumor component from
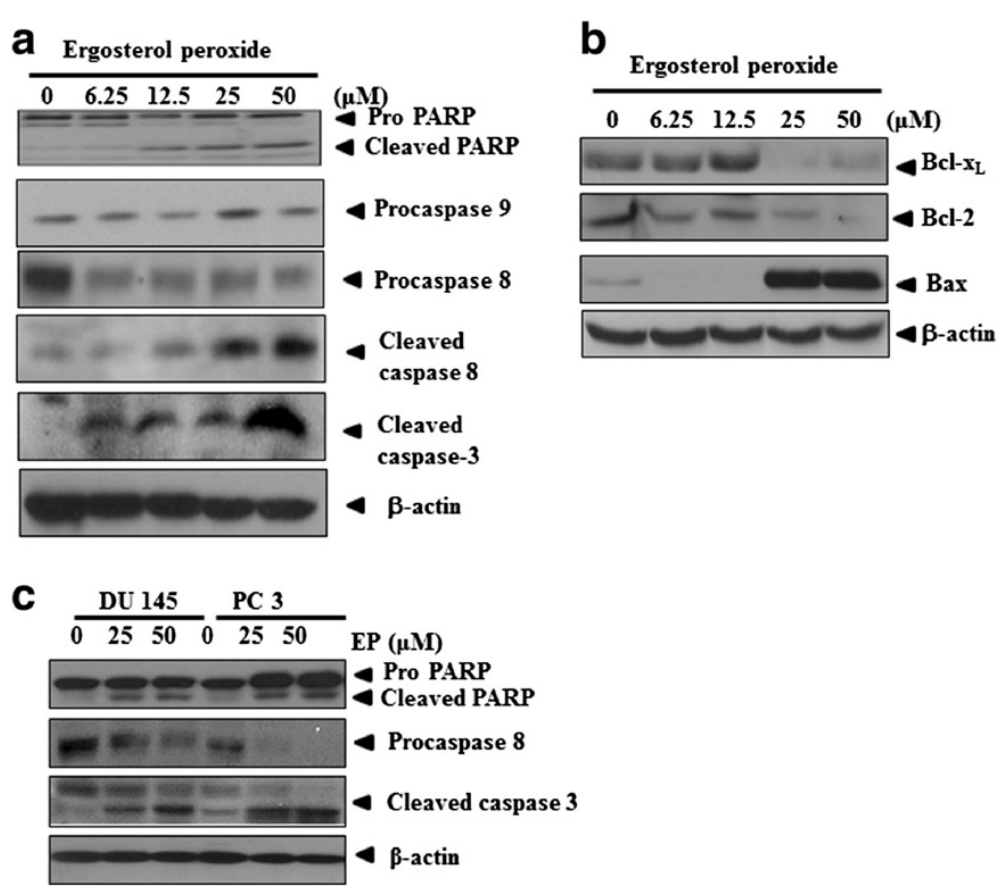

Figure 3 Effect of EP on PARP, procaspase 8/9, cleaved caspase 8/3, Bcl-2, Bcl-xL and Bax in DU 145 prostate cancer cells. (a, b) DU 145 cells were treated with various concentrations of $\mathrm{EP}(0,25,50,100$, and $200 \mu \mathrm{M})$ for $72 \mathrm{~h}$ and western blot was carried out with BCl-X, BCl-2, Bax, or $\beta$-actin antibodies to see apoptosis or survival related genes. (c) DU 145 and PC 3 cells were treated with EP $(25,50 \mu M)$ and western blot was carried out with PARP, procaspase 8 , cleaved caspase 3 or $\beta$-actin antibodies. 


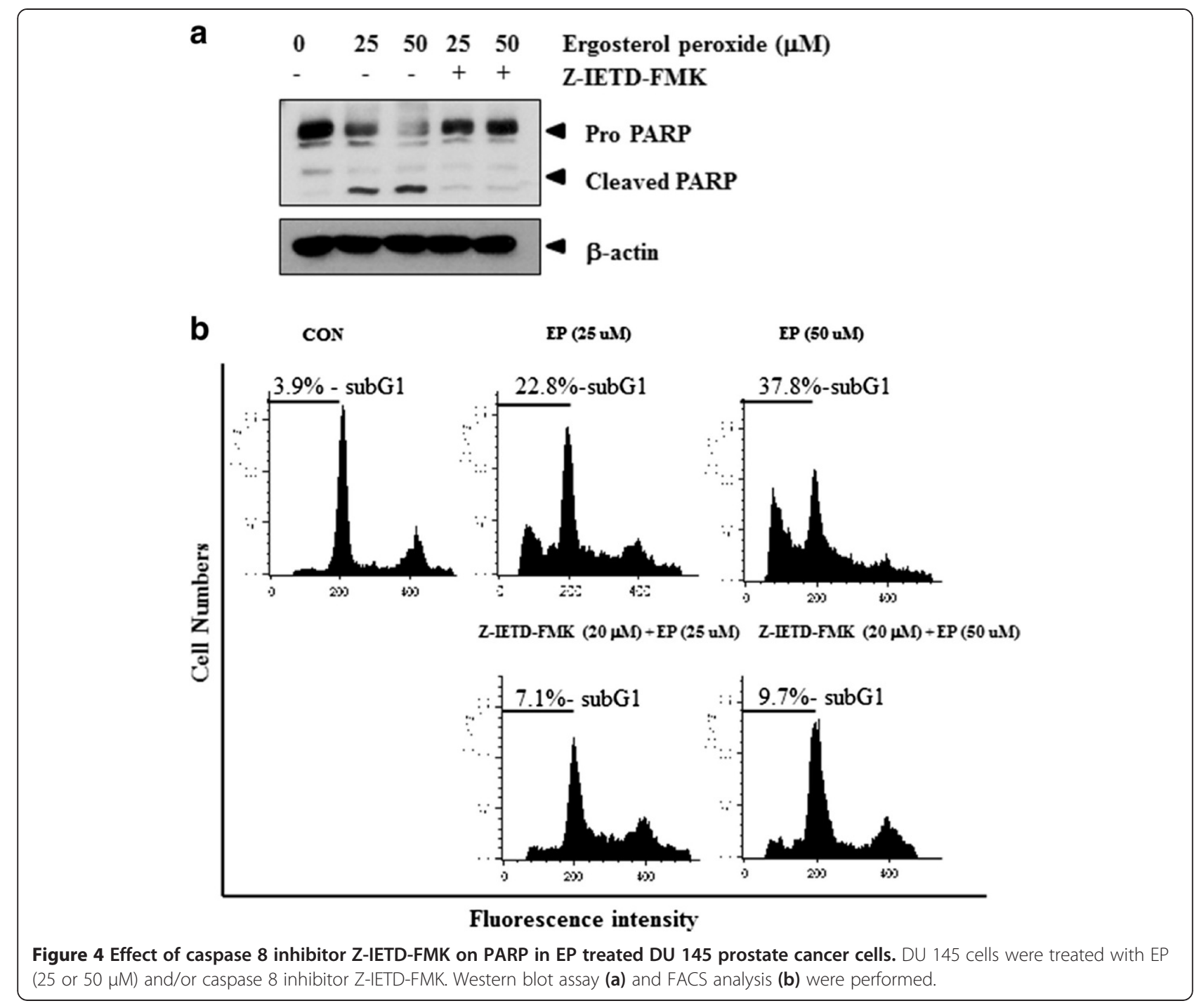

mushrooms was reported to have anti-inflammatory, antimicrobial, anti-tumor, anti-oxidative and immunosuppressive effects, the underlying antitumor mechanism of EP was not clearly understood in prostate cancer cells until now. Thus, to determine the potential of EP as a cancer chemopreventive agent or a dietary factor, in the current study, the apoptotic mechanism of EP was elucidated mainly in DU 145 prostate cancer cells.

EP showed the strong cytotoxic effect in the prostate cancer cells lines such as DU 145, PC 3 or M2182 compared to other cancer cells in a concentration dependent manner by MTT assay, implying its cytotoxic effect in prostate cancer cells. To confirm whether the cytotoxicity was induced through apoptosis induction, cell cycle analysis using flow cytometry and TUNEL assay was performed in DU 145 prostate cancer cells. EP significantly increased sub G1 population and the number of TUNEL positive green colored cells in DU 145 prostate cancer cells, indicating the apoptotic feature of EP since apoptosis accompanies with cell membrane wrinkled, DNA fragmentation, cytosol calcium increased and form the apoptotic body in the cells.

In general, there are two classical apoptotic pathways including intrinsic mitochondrial pathway and extrinsic death receptor pathway in cells [9]. In caspase-dependent mitochondrial pathway, cytochrome $c$ activates Apaf-1 and procaspase 9 , forming an apoptosome $[18,19]$. In contrast, the extrinsic signaling pathways initiate apoptosis via activation of caspase 8 and death receptors such as FasL/ FasR, TNF- $\alpha /$ TNFR 1, Apo3L/DR 3, Apo2L/DR 4 and Apo2L/DR 5 [20], while death receptor-mediated apoptosis can be inhibited by a protein called c-FLIP which will bind to FADD and caspase 8 [21,22]. Western blotting showed that EP cleaved PARP and caspase 8/3 without affecting caspase 9, attenuated the expression of 

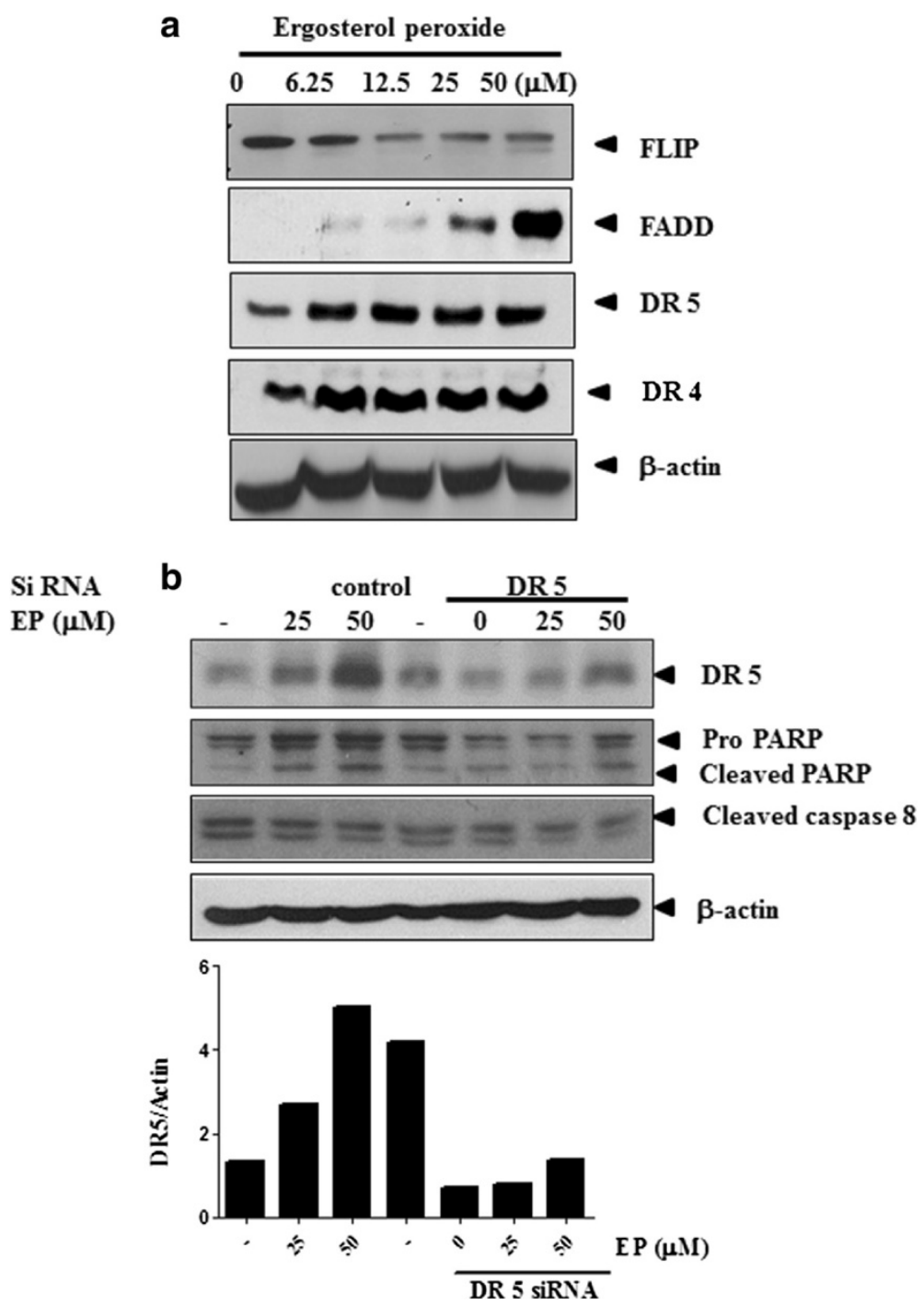

Figure 5 Effect of siRNA DR 5 transfection on PARP and procaspase 8 in EP treated DU 145 prostate cancer cells. (a) Western blot assay was carried out with indicated antibodies to see the expression of FLIP, FADD, DR 5 or DR 4 in EP treated DU 145 cells. (b) After transfection with siRNA DR 5, EP was treated and incubated in DU 145 cells for 24 h. The lysates were subjected to western blot analysis using DR 5, PARP, procaspase 8 or $\beta$-actin antibodies. Bar graph represents the relative expression of the DR 5 protein by using images J software.

anti-apoptotic proteins such as c-FLIP, $\mathrm{Bcl}_{-\mathrm{x}} \mathrm{L}$ and $\mathrm{Bcl}-2$ as well as activated the expression of proapoptotic protein Bax, FADD and DR 5 in a concentration dependent manner in DU 145 prostate cancer cells, strongly demonstrating death receptor dependent apoptosis by EP in DU 145 prostate cancer cells.

Furthermore, to confirm EP induced extrinsic apoptosis, caspase 8 inhibitor Z-IETD-FMK and siRNA DR 5 transfection were used in inhibitor study for EP mediated apoptosis. Z-IETD-FMK blocked the apoptotic ability of EP to cleave PARP and an increase of sub G1 population and the silencing of DR 5 suppressed the cleavages of PARP induced by EP in DU 145 prostate cancer cells, indicating the death receptor dependent apoptosis induced by EP.

\section{Conclusions}

In summary, EP showed significant cytotoxicity in DU 145 prostate cancer cells, increased sub G1 population and TUNEL positive cells, activated the cleavages of PARP and caspase 8/3 and Bax, FADD, and DR 5, but attenuated the expression of survival genes such as c-FLIP, $\mathrm{Bcl}_{-\mathrm{X}} \mathrm{L}$ and Bcl-2 in DU 145 prostate cancer cells. Collectively, our findings suggest that activation of death receptor 5 and caspase $8 / 3$ plays a key role in ergosterol peroxide induced apoptosis in DU 145 prostate cancer cells. 


\section{Competing interests}

The authors declare that they have no competing interests.

\section{Authors' contributions}

EJS, JHY and SHK designed the research and wrote manuscript. SK, BK, HL, KC, EJS, GW, SY, JL and MJK performed the research and analyzed the data. All authors read and approved the manuscript.

\section{Acknowledgements}

This work was supported by the Korea Science and Engineering Foundation (KOSEF) grant funded by the Korea government (MEST) (No. 2012-0005755).

Received: 23 June 2014 Accepted: 27 October 2014

Published online: 30 November 2014

\section{References}

1. Obertova Z, Brown C, Holmes M, Lawrenson R: Prostate cancer incidence and mortality in rural men-a systematic review of the literature. Rural Remote Health 2012, 12(2):2039.

2. Marchiani S, Tamburrino L, Nesi G, Paglierani M, Gelmini S, Orlando C, Maggi M, Forti G, Baldi E: Androgen-responsive and -unresponsive prostate cancer cell lines respond differently to stimuli inducing neuroendocrine differentiation. Int J Androl 2010, 33(6):784-793.

3. Meyer JP, Gillatt DA: PC-SPES: a herbal therapy for the treatment of hormone refractory prostate cancer. Prostate Cancer Prostatic Dis 2002, 5(1):13-15.

4. Jiang C, Lee HJ, Li GX, Guo J, Malewicz B, Zhao Y, Lee EO, Lee HJ, Lee JH, Kim MS, Kim SH, Lu J: Potent antiandrogen and androgen receptor activities of an Angelica gigas-containing herbal formulation: identification of decursin as a novel and active compound with implications for prevention and treatment of prostate cancer. Cancer Res 2006, 66(1):453-463.

5. Zhu H, Wu H, Liu X, Li B, Chen Y, Ren X, Liu CG, Yang JM: Regulation of autophagy by a beclin 1-targeted microRNA, miR-30a, in cancer cells. Autophagy 2009, 5(6):816-823.

6. Lee KS, Lee HJ, Ahn KS, Kim SH, Nam D, Kim DK, Choi DY, Ahn KS, Lu J, Kim SH: Cyclooxygenase-2/prostaglandin E2 pathway mediates icariside II induced apoptosis in human PC-3 prostate cancer cells. Cancer Lett 2009, 280(1):93-100.

7. Jiang C, Guo J, Wang Z, Xiao B, Lee HJ, Lee EO, Kim SH, Lu J: Decursin and decursinol angelate inhibit estrogen-stimulated and estrogen-independent growth and survival of breast cancer cells. Breast Cancer Res 2007, 9(6):R77.

8. Lee HJ, Lee HJ, Lee EO, Lee JH, Lee KS, Kim KH, Kim SH, Lu J: In vivo anti-cancer activity of Korean Angelica gigas and its major pyranocoumarin decursin. Am J Chin Med 2009, 37(1):127-142.

9. Ouyang L, Shi Z, Zhao S, Wang FT, Zhou TT, Liu B, Bao JK: Programmed cell death pathways in cancer: a review of apoptosis, autophagy and programmed necrosis. Cell Prolif 2012, 45(6):487-498.

10. Trzoss L, Fukuda T, Costa-Lotufo LV, Jimenez P, La Clair JJ, Fenical W: Seriniquinone, a selective anticancer agent, induces cell death by autophagocytosis, targeting the cancer-protective protein dermcidin. Proc Natl Acad Sci U S A 2014, 111(41):14687-14692.

11. Arora S, Singh S, Piazza GA, Contreras CM, Panyam J, Singh AP: Honokiol: a novel natural agent for cancer prevention and therapy. Curr Mol Med 2012, 12(10):1244-1252.

12. Takei T, Yoshida M, Ohnishi-Kameyama M, Kobori M: Ergosterol peroxide, an apoptosis-inducing component isolated from Sarcodon aspratus (Berk.) S. Ito. Biosci Biotechnol Biochem 2005, 69(1):212-215.

13. Rhee YH, Jeong SJ, Lee HJ, Lee HJ, Koh W, Jung JH, Kim SH, Sung-Hoon K: Inhibition of STAT3 signaling and induction of SHP1 mediate antiangiogenic and antitumor activities of ergosterol peroxide in U266 multiple myeloma cells. BMC Cancer 2012, 12:28.

14. Kobori M, Yoshida M, Ohnishi-Kameyama M, Shinmoto H: Ergosterol peroxide from an edible mushroom suppresses inflammatory responses in RAW264.7 macrophages and growth of HT29 colon adenocarcinoma cells. Br J Pharmacol 2007, 150(2):209-219.

15. Lindequist $U$, Niedermeyer TH, Julich WD: The pharmacological potential of mushrooms. Evid Based Complement Alternat Med 2005, 2(3):285-299.

16. Lima CU, Cordova CO, Nobrega Ode T, Funghetto SS, Karnikowski MG: Does the Agaricus blazei Murill mushroom have properties that affect the immune system? An integrative review. J Med Food 2011, 14(1-2):2-8.
17. Wu MF, Chen YL, Lee MH, Shih YL, Hsu YM, Tang MC, Lu HF, Tang NY, Yang ST, Chueh FS, Chung JG": Effect of Agaricus blazei Murrill extract on HT-29 human colon cancer cells in SCID mice in vivo. In Vivo 2011, 25(4):673-677.

18. Fulda S, Debatin KM: Extrinsic versus intrinsic apoptosis pathways in anticancer chemotherapy. Oncogene 2006, 25(34):4798-4811.

19. Huang DM, Shen YC, Wu C, Huang YT, Kung FL, Teng CM, Guh JH: Investigation of extrinsic and intrinsic apoptosis pathways of new clerodane diterpenoids in human prostate cancer PC-3 cells. Eur J Pharmacol 2004, 503(1-3):17-24.

20. Gupta S: Molecular signaling in death receptor and mitochondrial pathways of apoptosis (Review). Int J Oncol 2003, 22(1):15-20.

21. Scaffidi C, Schmitz I, Krammer PH, Peter ME: The role of C-FLIP in modulation of CD95-induced apoptosis. J Biol Chem 1999, 274(3):1541-1548.

22. Raclaw KA, Heemers HV, Kidd EM, Dehm SM, Tindall DJ: Induction of FLIP expression by androgens protects prostate cancer cells from TRAIL-mediated apoptosis. Prostate 2008, 68(15):1696-1706.

doi:10.1186/s12935-014-0117-5

Cite this article as: Han et al:: Upregulation of death receptor 5 and activation of caspase $8 / 3$ play a critical role in ergosterol peroxide induced apoptosis in DU 145 prostate cancer cells. Cancer Cell International 2014 14:117.

\section{Submit your next manuscript to BioMed Central and take full advantage of:}

- Convenient online submission

- Thorough peer review

- No space constraints or color figure charges

- Immediate publication on acceptance

- Inclusion in PubMed, CAS, Scopus and Google Scholar

- Research which is freely available for redistribution

Submit your manuscript at www.biomedcentral.com/submit
C BioMed Central 